\title{
"EU APOSTO 1 DÓLAR QUE VOCÊ NÃO ENTENDEU 99\% DO QUE EU ESCREVI": SOBRE POSICIONAMENTOS IDENTITÁRIOS, FACEBOOK E PRÁTICAS COMUNICATIVAS DE SUJEITOS MULTILÍNGUES
}

\author{
“I Bet \$1 That You Didn't Understand 99\% of What I Wrote”: On \\ Positioning Identities, Facebook, and Multilinguals' Communicative \\ Practices
}

Diogo Oliveira do Espírito SANTO

Universidade Federal do Recôncavo da Bahia diogo.oliveira@ufrb.edu.br

https://orcid.org/0000-0003-4805-4430

\begin{abstract}
RESUMO: Este artigo investiga as formas através das quais sujeitos multilíngues empregam uma variedade de recursos linguísticosemióticos como um ato de posicionamento em interações no Facebook. Parte-se dos conceitos de posição e posicionamento (HARRÉ; VAN LANGENHOVE, 1999), posturas (BARTON; LEE, 2015) e práticas translíngues ou translinguagem (CANAGARAJAH, 2013; GARCÍA; WEI, 2014; ROCHA; MACIEL, 2015) para se discutir práticas comunicativas em que sujeitos negociam diferentes posições identitárias. Para isso, dados de uma pesquisa de natureza netnográfica (KOZINETS, 2010; 2020) servirão de base para a análise de um post de Facebook, bem como para apresentar o contexto da investigação e o sujeito participante. Exploram-se, portanto, as possibilidades oferecidas por perspectivas pós-estruturalistas e discursivas para a compreensão dos processos de negociação identitária marcados por espaços digitais de ação pela linguagem.
\end{abstract}

PALAVRAS-CHAVE: Posicionamentos identitários; Multilinguismo; Facebook.

\begin{abstract}
This article examines the ways through which multilinguals employ a wide range of linguistic-semiotic resources as a positioning act in Facebook interactions. Based on the concepts of position and positioning (HARRÉ; VAN LANGENHOVE, 1999), stances (BARTON; LEE, 2015), and translingual practices or translanguaging (CANAGARAJAH, 2013; GARCÍA; WEI, 2014; ROCHA; MACIEL, 2015), it discusses communicative practices in which subjects negotiate different identity positions. For this purpose, data from a larger netnographic research (KOZINETS, 2010; 2020) will serve as a basis for the analysis of a Facebook post, as well as for the
\end{abstract}


introduction of the research context and its participant. Therefore, it explores the affordances of post-structuralist and discursive approaches to further our understanding of digital language practices in the context of identity negotiation.

KEYWORDS: Identity positioning; Multilingualism; Facebook.

\section{INTRODUÇÃO}

Segundo dados do Data Reportal (2019) ${ }^{1}$, mais de dois bilhões de pessoas ao redor do mundo fazem uso regular do Facebook. Esse fato evidencia o importante papel de sites de redes sociais nas práticas sociais cotidianas de mais de dois terços da população mundial que usa algum aparelho digital (KOZINETS, 2020). Como resultado, uma gama de estudos tem sido desenvolvida a fim de investigar os impactos dessas plataformas nos mais variados âmbitos de nossas vidas. No campo da linguagem, área de interesse deste artigo, pesquisas como as de Zhao et al. (2008), Bolander e Locher (2010; 2015), Barton e Lee (2015), Sharma (2012), Sultana et al. (2013; 2015), Leppänen et al. (2015) entre outros, têm se interessado em como práticas comunicativas no Facebook estão intimamente ligadas às identidades dos sujeitos. Esses autores se deslocam de estudos centrados na ideia de identidades online como separadas e "menos reais" do que aquelas da comunicação offline e se fundamentam na noção de linguagem como prática social, em que as identidades são percebidas como multifacetadas e interligadas a contextos socioculturais mais amplos (BOLANDER; LOCHER, 2015).

A partir da chamada virada social nos estudos da linguagem (BLOCK, 2003), o estado da arte das pesquisas sobre o tema tem apontado para uma aproximação com perspectivas teórico-metodológicas que compartilham o entendimento de identidade como performances discursivas (BOLANDER, 2017). Essas pesquisas (BOLANDER; LOCHER, 2015; BARTON; LEE, 2015) não só partem, mas também expandem propostas pós-estruturalistas sobre os processos de construção identitária como aquelas embasadas na Teoria dos Posicionamentos (DAVIES; HARRÉ, 1990; HARRÉ; VAN LANGENHOVE, 1999; BUCHOLTZ; HALL, 2005). Essa abordagem sociopsicológica compreende identidade como o posicionamento de si e do outro, enfatizando, assim, que

\footnotetext{
1 Dados disponíveis na página: <https://datareportal.com/reports/digital-2019-global-digital-overview>. Acesso em: 29 jun. 2020.
} 
ela não ocorre num vácuo social e nem preexiste à interação, mas que emerge das práticas discursivas. Mais contemporaneamente, a despeito do foco em interações face a face, os pressupostos da Teoria dos Posicionamentos têm sido revisitados a fim de acomodar o impacto da comunicação digital nas práticas de linguagem atuais, como é o caso dos estudos de Barton e Lee (2015) sobre a noção de posturas.

Neste artigo, tais arcabouços serão mobilizados para a reflexão sobre como práticas comunicativas online ${ }^{2}$ revelam diferentes posições identitárias de sujeitos multilíngues ${ }^{3}$ no Facebook. Para isso, atrelarei à proposta da Teoria dos Posicionamentos e das posturas, perspectivas focadas no bi/multilinguismo a partir da noção de translinguagem ou práticas translíngues (CANAGARAJAH, 2013; GARCÍA; WEI, 2014; WEI, 2018), englobando propostas teórico-metodológicas centradas no desafio a ideologias monolíngues que visam silenciar a diversidade linguístico-cultural dos nossos tempos (MACIEL; ROCHA, 2020).

Com o propósito de abordar as implicações dessas teorizações para o estudo da linguagem online, analisarei dados gerados em uma pesquisa de doutorado ${ }^{4}$, cuja ênfase está na problematização das maneiras através das quais sujeitos multilíngues se valem de uma gama de recursos linguístico-semióticos em práticas comunicativas online para se posicionar e construir sentido localmente. Desse modo, através de uma breve análise de um post de Facebook, buscarei ilustrar as potencialidades oferecidas pela Teoria dos Posicionamentos/postura, bem como pelos princípios da translinguagem na maneira como entendemos e investigamos os processos de construção identitária marcados pelos espaços digitais de negociação de sentido.

\footnotetext{
${ }^{2}$ Termo usado para fazer referência às práticas comunicativas em espaços virtuais mediados pela tecnologia digital.

${ }^{3}$ Deve-se ter em mente que o "multi”, como adotado neste estudo, não se refere às diferentes línguas faladas pelos sujeitos, mas sim às complexas práticas de linguagem nas quais eles se envolvem. Nesse sentido, o termo pode vir a ser usado, inclusive, para caracterizar sujeitos comumente definidos como "mono" e/ou "bilíngues", uma vez que esses também se envolvem em práticas de linguagem que englobam diferentes recursos linguísticos que não são facilmente reconhecidos como pertencentes a uma ou outra (variedade de) língua nacional, como o português, inglês etc. Mais adiante, o leitor perceberá que a perspectiva adotada neste artigo, qual seja, a translíngue, servirá como suporte teórico para problematizar o que se entende por multilinguismo e sujeitos multilíngues.

${ }^{4}$ A pesquisa, ainda em andamento, foi aprovada por um Comitê de Ética em Pesquisa da Universidade Federal da Bahia, sob parecer de número 3.168.263.
} 


\section{SOBRE POSIÇÕES E POSICIONAMENTOS IDENTITÁRIOS}

Com a publicação de Positioning: The Discursive Production of Selves, Browny Davies e Rom Harré (1990) apresentam as bases do que mais tarde seria chamado de Teoria dos Posicionamentos (doravante TP). Influenciada pela virada discursiva nos estudos em Psicologia (HARRÉ; GILLET, 1994), a TP se fundamenta na percepção de que os sujeitos constroem suas próprias identidades enquanto atribuem identidades a outrem em interações locais. A proposta defende uma análise sociointeracional, em que se acentua o caráter dinâmico das posições negociadas pelos sujeitos no discurso em oposição a conceitos estáticos e determinísticos sobre os processos de negociação identitária. Apesar de sua origem na Psicologia Social, a TP tem sido empregada em diferentes campos de pesquisa, quais sejam, na Educação (SAITO; RIBEIRO, 2013; HERBEL-EISENMANN et al., 2015), Linguística Aplicada (KAYI-AYDAR, 2019), Estudos Organizacionais (BROWN, 2015), Comunicação intercultural (SLOCUMBRADLEY, 2008) entre outros.

A Teoria dos Posicionamentos (DAVIES; HARRÉ, 1990; HARRÉ; VAN LANGENHOVE, 1999) investiga as maneiras como os sujeitos, discursivamente, agem uns em relação aos outros no processo de construção de suas posições identitárias. Seu principal objetivo é compreender o comportamento não como uma mera resposta a um estímulo, mas como um ato de ação social. Portanto, um ponto central das propostas dessa teoria é a noção de prática discursiva e atos de fala.

Dentre os estudiosos que oferecem pressupostos para essa investigação, encontram-se Bakhtin/Volochinov (1995 [1929]), Foucault (2009 [1969]), Austin (1990 [1962]) e Searle (1979). Esses autores são evocados para se problematizar como a tomada de posição se configura como uma forma de ação social, possibilitada, em sua grande parte, por atos de fala, não tomados como tendo uma estrutura fixa ou estática, mas sim desenvolvidos no fluxo da interação.

Alinhado a essa perspectiva, o discurso é compreendido como a prática institucional da linguagem, e essa é definida como uma ação social histórica e ideologicamente orientada. Portanto, o discurso não é percebido como algo localizado na mente dos sujeitos, mas como um processo dinâmico e coletivo através do qual os sentidos são construídos, adquiridos e transformados. Logo, segundo os pressupostos da teoria, o 
que falamos não são apenas palavras. O que é dito, como é dito e por quem é dito ao mesmo tempo que situa e define o outro, nos situa e nos define como sujeitos.

Através dessa convergência de perspectivas teóricas, a TP, por fim, busca compreender como atribuímos, ganhamos ou negociamos direitos e deveres a partir de linhas narrativas específicas. Por isso, faz-se necessário tratar como seus principais estudiosos entendem por posição e posicionamento, direitos e deveres e linhas narrativas ou storylines nos processos de negociação identitária ${ }^{5}$ e discutir tais construtos atrelandoos aos objetivos da investigação aqui proposta.

\section{Posição e posicionamento}

Segundo Harré e van Langenhove (1999), o posicionamento é

[...] a construção discursiva de narrativas pessoais que fazem das ações de uma pessoa inteligíveis e relativamente determinadas pelos atos sociais em que os membros de uma conversa têm posições específicas. (HARRÉ;VAN LANGENHOVE, 1999, p. 16) ${ }^{6}$.

Esses autores indicam, assim, que enquanto alguns atos sociais são reconhecidos e inteligíveis para os participantes de um evento discursivo, outros podem ser questionados e não aceitos.

A importância de se definir posição e posicionamentos está atrelada à crítica a estudos sobre identidades em paradigmas mais "rígidos", como aqueles realizados por Goffman (1959), a partir da noção de "papéis", isto é, categorias fixas ocupadas pelos sujeitos nos processos de interação às quais seriam associadas expectativas sobre determinadas funções sociais. Diferentemente dessa visão, a TP advoga que construímos identidades, discursivamente, através da performance de categorias relacionadas ao que conhecemos como gênero, raça, classe e identidade pessoal e social disponíveis nas interações. Essas identidades, ao contrário de "papéis", são condicionadas socialmente e co-construídas pelos envolvidos em tais práticas. Com isso, ao invés de se definir

\footnotetext{
${ }^{5}$ Corroboro a noção de negociação identitária como proposta por Pavlenko e Blackledge (2004), para os quais esse processo se caracteriza como a tensão ocasionada pela interação entre a forma como os sujeitos se posicionam com a tentativa de reposicionamento ou contestação de uma posição atribuída a eles.

${ }^{6}$ Todas as traduções de língua estrangeira são de minha responsabilidade.
} 
identidade em termos de categorias estáticas ou meras funções atribuídas às pessoas, o posicionamento oferece aos sujeitos a "opção" de aceitar ou rejeitar suas posições. Dessa forma, as categorias de gênero, raça entre outras passam também a ser compreendidas como socialmente orientadas e, por isso, variáveis e negociadas no discurso.

Nas palavras de Tan e Moghaddam (1995, p. 187, grifo dos autores):

\begin{abstract}
Importante para o conceito de posicionamento é a ideia de que as posições são ativamente negociadas e alcançadas, ao invés de atribuídas e passivamente recebidas. Posições discursivas não são 'locais' preexistentes, meramente 'ocupados' em práticas discursivas, mas são imanentes e se tornam colaborativamente disponíveis e realizadas por falantes no próprio ato da conversa.
\end{abstract}

Portanto, atribuir a outros ou ser atribuído posições através de atos de fala é o que se pode chamar de posicionamento.

Para Harré e van Langenhove (1999), as identidades são construídas levando em consideração diversos aspectos da vida social. Esses autores esclarecem que toda e qualquer análise de construção identitária deve levar em consideração, ao menos, três níveis de interação: interpessoal, institucional e cultural. Apesar de separar as práticas discursivas nesses três grandes níveis, Harré e van Langenhove (1999) reconhecem o perigo de se pensar a sociedade como a união de três partes independentes (com cada uma sendo pesquisada por ciências diferentes, quais sejam, a Psicologia, a Psicologia Social e a Sociologia). Ao invés disso, esses autores advogam que o mundo social consiste em um único grande domínio de interações, nas quais fenômenos sociais e psicológicos são gerados contínua e concomitantemente. Logo, qualquer tentativa de se definir identidade ignorando a complexidade entre as relações interpessoais, institucionais e culturais produzidas em sociedade deve ser vista com cuidado.

Por essas razões, Harré e van Langenhove (1999) indicam que o que chamamos de identidade é, na verdade, um processo contínuo e repetido de tomada de posições em seus diferentes níveis de interação. Por isso, o que entendemos por identidade, seja ela sociocultural (como pertencimento a uma etnia, a uma classe social, ou como "papéis" sociais como pai, mãe, professor, aluno) ou pessoal (formada por atributos que associamos a nosso "eu" em comparação aos dos outros) é, portanto, um processo de tomada de posições circunscritas nas nossas experiências individuais e coletivas, e nas práticas 
repetidas que desenvolvemos com outros sujeitos e contextos ${ }^{7}$.

\section{Direito, deveres e storylines}

Uma posição é, na verdade, um conjunto de direitos e deveres distribuídos através de atos de posicionamentos. Segundo Harré e Slocum (2003), direitos são justificativas prévias para a propriedade de se dar ou pedir ações de outras pessoas, enquanto os deveres são as expressões prévias de comandos para uma ação. Assim, a construção de sentido através do discurso se dá nesse jogo entre sujeitos que alegam ter direitos de mandar, obrigar ou pedir algo e outros que aceitam ou desafiam os deveres impostos.

Os direitos e deveres construídos nas interações ganham sentido através do que Harré e van Langenhove (1999) chamam de storylines (linhas narrativas/contextos sociais). De acordo com esses autores, as posições que os sujeitos ocupam estarão sempre relacionadas a contextos sociais mais amplos, uma vez que elas emergem de padrões de interação relativamente estáveis. Associado a isso, Harré e van Langenhove (1999) reforçam que nem as narrativas e nem as posições são construídas livremente, pois os sujeitos envolvidos nas práticas de linguagem negociam suas identidades na interrelação entre posições/atos comunicativos/narrativas. Logo, as storylines, segundo HerbelEisenmmann et al. (2015), são tanto o conjunto de repertórios já moldados culturalmente, como contextos que emergem enquanto os sujeitos interagem uns com os outros.

Assim sendo, é pertinente afirmar que é na intersecção entre posições, direitos, deveres e storylines que somos capazes de reivindicar, negar e dar direitos, assim como exigir determinados deveres. Isso significa dizer que os sujeitos, através de atos de fala e seus consequentes efeitos, podem limitar ou permitir determinadas ações discursivas.

Outro aspecto fundamental na investigação de como as identidades são negociadas nos termos da TP é a elucidação dos modos como os processos de posicionamentos ocorrem. Segundo Harré e van Langenhove (1999), esses podem ser divididos em outros

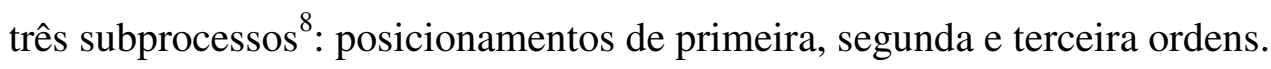

\footnotetext{
7 Parece-me adequado relacionar os princípios da Teoria dos Posicionamentos aos estudos sobre performance e performatividade desenvolvidos, principalmente, a partir da Teoria Queer. Para mais detalhes sobre essa perspectiva, sugiro a leitura de Butler (1990), Pennycook (2007), Coupland (2007) e Moita Lopes (2013).

${ }^{8}$ Uma vez que a Teoria dos Posicionamentos oferece um vasto quadro de opções analíticas (que, muitas 
Grande parte dos posicionamentos de primeira ordem é tácito, isto é, os sujeitos nem sempre se posicionam ou posicionam outros intencionalmente. Nesse estágio, as posições atribuídas não são desafiadas e quando resultam em ação são chamadas de posicionamento performativo. Quando, no entanto, o posicionamento de primeira ordem é questionado, tem-se o que se chama de posicionamento de segunda ordem. Essa prática é também conhecida como reposicionamento, uma vez que os sujeitos reivindicam direitos e deveres como forma de desafiar o posicionamento inicial, ou então, como uma maneira de negar alguém o direito de posicionar outros. Esse processo ocorre, portanto, quando há a necessidade de se questionar ou negociar posicionamentos de primeira ordem. Nesse caso, posicionamentos iniciais podem ser desafiados e os falantes reposicionados (HARRÉ; VAN LANGENHOVE, 1999). Há ainda o processo de negociação de terceira ordem. Esse estágio caracteriza discussões retrospectivas de atos de posicionamentos prévios, ou seja, esse posicionamento ocorre fora da interação original, uma vez que descreve ações que aconteceram antes da interação atual.

A despeito de a teoria se alicerçar nos estudos dos atos de fala, atualmente, tem-se defendido a inclusão do termo "atos comunicativos" (HERBEL-EISENMANN et al., 2015), uma vez que outros recursos semióticos tais como prosódia, gestos, expressões faciais e, mais contemporaneamente, recursos digitais, também contribuem para o posicionamento. Nesse sentido, as posições passam a ser interpretadas como atribuições semioticamente estruturadas ligadas às ações discursivas e cumpridas através de eventos sociais específicos (DEPPERMANN, 2015). Essa perspectiva é valiosa para a compreensão das práticas de linguagem de sujeitos multilíngues nas redes sociais como práticas identitárias, uma vez que aponta para o caráter multissemiótico (ROJO, 2012) da construção de sentido. Assim, a escolha de diferentes semioses (e não apenas de línguas) em interações locais pode posicionar os sujeitos de diferentes formas, representando, assim, as múltiplas identidades envolvidas nos processos de negociação online.

vezes, se sobrepõem), esses subprocessos são apenas alguns dos arcabouços que pesquisadores podem seguir para empreender suas análises. Devido às limitações de espaço, irei me ater apenas a essa proposta por achála mais adequada aos objetivos deste artigo. 


\section{SOBRE POSICIONAMENTOS E POSTURAS ONLINE}

Ao passo que a escolha de línguas é ponto central para o posicionamento identitário no Facebook, tem crescido a compreensão de que a maneira como os sujeitos combinam imagens e outros recursos audiovisuais para negociar sentidos também é um modo de posicionar a si e o outro. Essa concepção é levada à risca por Barton e Lee (2015), que afirmam que um dos caminhos mais produtivos para se investigar os processos de negociação identitária é discutir como os sujeitos mobilizam seus recursos linguísticosemióticos em diferentes situações para fins diversos e com diferentes pessoas.

Ao partirem da concepção de que "[...] identidade online não diz respeito apenas a quem somos, mas também a quem queremos ser para os outros, a como os outros nos veem [...]" (BARTON; LEE, 2015, p. 94, grifos dos autores), Barton e Lee (2015, p. 118) oferecem pano de fundo para entender a dinâmica da negociação identitária online alicerçada na ideia de posturas, isto é, o "[...] posicionamento das pessoas em relação a si mesmas, ao que é dito, e a outras pessoas ou objetos [...]”. Segundo esses autores, o posicionamento é um ato discursivo fundamental na interação online. Além disso, ele não se limita apenas a expressar opiniões de quem se posiciona pela escolha cuidadosa de vocabulário e outros recursos. Barton e Lee (2015) afirmam que os sujeitos também podem querer reforçar um senso único do "eu", a fim de se destacarem numa comunidade mais ampla de pessoas que se posicionam.

A ideia central levantada por Barton e Lee (2015) é a de que as novas mídias oferecem novas possibilidades de posicionamentos e interações, já que os sujeitos podem experimentar e agir nos espaços digitais com diferentes línguas e recursos semióticos, oportunizando, assim, a criação de encontros multilíngues.

Esses autores reconhecem que, ao se envolverem em práticas multilíngues, os sujeitos lançam mão de diferentes recursos para destacarem diferentes aspectos de suas identidades. A escolha desses recursos depende de uma gama de relações contextuais, expressando a tentativa de os sujeitos projetarem uma determinada identidade para um público específico e, às vezes, imaginado (MARWICK; boyd, 2010).

De acordo com Barton e Lee (2015), no Facebook, por exemplo, os sujeitos sabem e podem controlar, em certa medida, quem lê o que em seus perfis, já que, com frequência, eles conhecem sua audiência, ou os seus "amigos". Tendo isso em mente, os usuários 
dessa rede social muitas vezes negociam a opção de recursos semióticos, incluindo as línguas que compõem os seus repertórios, levando em conta o tipo de identidade que desejam performar para um público específico. Essa opção de recursos está, assim, estritamente relacionada ao grau em que os sujeitos pretendem se projetar como membros globais ou locais no Facebook.

Essa discussão se mostra produtiva no que concerne à noção de que a tomada de postura, isto é, dos atos de posicionamento e alinhamento em relação aos outros, é útil para compreender como as identidades são negociadas online. Além disso, ela aponta para o fato de que a escolha semiótica atua como uma estratégia através da qual os sujeitos buscam se diferenciar e criar suas próprias vozes em espaços multilíngues.

O conceito de postura é central para a compreensão de como os sujeitos se posicionam nas redes sociais. Nesses espaços, as possibilidades de interação através da escrita multimodal (KRESS; VAN LEEUWEN, 2001) abrem caminhos para que os sujeitos produzam, compartilhem, confrontem e avaliem opiniões através de uma variedade de textos e modalidades. No Facebook, a postura não é tomada isoladamente por um único sujeito, mas é constantemente criada e renegociada entre os seus usuários, através das ferramentas disponíveis aos seus dedos, como a opção de "curtir" e comentar em uma postagem, por exemplo.

Estudos linguísticos sobre posturas e posicionamentos tendem a lançar mão da análise gramatical, bem como do léxico empregado. Um exemplo pode ser encontrado em Myers (2010), que empreende uma subdivisão nos atos de postura em postura epistêmica e afetiva. Na postura epistêmica, é analisada a tomada de posição a partir do uso de verbos que indicam certeza, crenças e conhecimentos, como "achar", "imaginar" e "saber". A postura afetiva, pelo contrário, é marcada pela expressão de atitudes e sentimentos sobre o que é postado e lido, tais como "eu adoro", "eu amo", "que incrível” etc.

Apesar de suas contribuições para a investigação sobre os processos de negociação identitária nas redes sociais, se pode observar que nesses estudos a análise dos posicionamentos é realizada através de meios estritamente linguísticos. Para Barton e Lee (2015), de forma contrária às pesquisas sobre comunicação monomodal, as redes sociais evidenciaram que a interação, bem como as posturas são de natureza multimodal, envolvendo a mescla de diferentes recursos linguístico-semióticos disponíveis aos sujeitos 
para a construção de sentido. É nesse contexto que se torna essencial discutir o papel da perspectiva translíngue nos estudos sobre as práticas de linguagem de nossos tempos.

\section{SOBRE TRANSLINGUAGENS E IDENTIDADES}

Nos últimos anos, tem havido um crescente interesse em pesquisas sobre a relação entre linguagem e globalização, acompanhado pela emergência de novos termos, frequentemente liderados pelos afixos "super" e "trans", como uma tentativa de não só se repensar os pressupostos dos campos da linguagem, como a Sociolinguística e a Linguística Aplicada, como também acomodá-los aos efeitos da imigração e da comunicação transnacional (BLOMMAERT, 2010).

Tais propostas têm problematizado noções como mono/bi/multilinguismo por não serem adequadas para a reflexão sobre os repertórios construídos a partir da diversidade de recursos linguístico-culturais que caracterizam os contextos de interação contemporâneos. Dentre elas, as práticas translíngues (CANAGARAJAH, 2013; ROCHA; MACIEL, 2015) e/ou a translinguagem (GARCÍA; WEI, 2014; WEI, 2018) têm ganhado espaço considerável na investigação sobre a complexidade dos processos comunicativos em que uma gama de recursos multissemióticos são empregados como atos de posicionamentos identitários. Segundo essas orientações, não é só difícil e, muitas vezes, improdutivo relacionar características linguísticas a línguas específicas, como também fica claro que o movimento entre línguas, linguagens e demais recursos demanda novas teorizações (SULTANA et al., 2015).

Ofelia García (2009), um dos nomes mais relevantes nesses estudos, argumenta que a adoção de uma lente "trans" oferece a pesquisadores, professores e a políticas educacionais a possibilidade de transcender pressupostos já enraizados sobre língua, educação bilíngue e sujeitos bi/multilíngues. Nesse contexto, a translinguagem pode ser tanto um termo para definir as múltiplas práticas discursivas em que bi/multilíngues se envolvem no intuito de criar sentido de seus mundos (GARCÍA, 2009), uma teoria prática da linguagem (WEI, 2018) e como uma prática pedagógica em que os recursos linguísticosemióticos dos sujeitos são valorizados no processo de ensino e aprendizagem (CREESE; BLACKLEDGE, 2010). Entretanto, Canagarajah (2017) deixa claro que a translinguagem não deve ser tomada como um modelo universal aplicável a todos os contextos. Pelo 
contrário, ela deveria ser definida como uma prática situacional e mutável e não uma teoria estática. Segundo esse autor, se tratarmos a translinguagem como prática, sociolinguistas e linguistas aplicados estarão abertos às implicações inovadoras dessa teorização em diferentes contextos e condições históricas. Contrária à noção de codeswitching (GUMPERZ, 1982; MYERS-SCOTTON, 1993), que define línguas como códigos separados e independentes, a translinguagem representa as línguas como parte de um único sistema coerente através do qual os sujeitos podem se expressar, levando em consideração fatores contextuais, sociais e culturais. Para Pennycook (2008), a noção de língua que embasa tal proposta é aquela que ressalta a comunicação como transcendendo as barreiras linguísticas, isto é, a língua não é vista tanto como um sistema homogêneo a partir do qual nos comunicamos, mas sim como uma atividade social. Portanto, como advogam Rocha e Neto (2020, p. 2), a translinguagem se configura tanto como "[...] filosofia, como espaços de crise e criatividade, como um conjunto de práticas pedagógicas, como discursos, ideologias e políticas potencialmente transgressoras [...]".

Em contextos de linguagem online, é possível observar que sujeitos, sejam eles comumente definidos como mono, bi ou multilíngues, se envolvem em práticas translíngues, já que a maioria se vale de recursos variados para cumprir seus propósitos comunicativos. Embora não sejam necessariamente proficientes nas línguas que empregam, esses sujeitos se movem por entre e além de diferentes registros, estilos e modos comunicativos, refletindo, assim seus repertórios multilíngues móveis (PENNYCOOK; OTSUJI, 2015). Portanto, é possível que qualquer sujeito que se comunique através de tecnologias digitais se encontre envolvido em práticas que transcendam o que se costuma entender por línguas e identidades. Com isso, frente ao que foi exposto, fica clara a pertinência de se adotar o construto da translinguagem como ponto de partida para a análise das práticas de linguagem negociadas em sites de rede social.

O caráter multimodal e transformador desse construto será acentuado a partir da imbricação com os outros dois pressupostos apresentados, quais sejam, posicionamento e postura. A partir dessa interação, será possível inferir as formas através das quais os sujeitos se valem de diferentes recursos para dar pistas de suas identidades em interações online locais. Antes de avançar nesse aspecto, entretanto, se faz necessário abordar a 
natureza da pesquisa, bem como apresentar dados do sujeito e do post escolhidos para ilustrar o debate aqui em curso.

\section{SOBRE A PESQUISA}

O estudo que dá base à discussão proposta neste texto faz parte de uma pesquisa de natureza netnográfica. Como um tipo de etnografia, a netnografia se alinha às recentes investigações qualitativas de base antropológica e social e, como tais, se configura como um tipo de bricolage entre diferentes perspectivas, compartilhando com elas os seguintes fundamentos: o foco na experiência humana e compreensão cultural, o interesse pelos contextos cotidianos das pessoas, a investigação dos sistemas sociais de construção de sentido e a inclusão da interpretação das práticas culturais tanto dos pesquisadores como dos “pesquisados" (KOZINETS, 2020).

Logo, como ocorre na maioria das práticas etnográficas, a netnografia faz uso de observação participante, entrevistas e outros instrumentos de geração de dados disponíveis ao pesquisador. Entretanto, para Kozinets (2010), a netnografia não é simplesmente um outro nome para a etnografia feita online, mas sim um modo específico de se fazer pesquisa qualitativa a partir da combinação de diferentes métodos e procedimentos (KOZINETS, 2020), exclusivamente, online.

Segundo Kozinets (2010), existem alguns procedimentos para se realizar a geração de dados numa pesquisa que se propõe netnográfica. Esse autor discute tais modos a partir dos conceitos de dados de arquivo, dados suscitados e dados de anotação. Os dados de arquivo são aqueles pouco afetados pela ação do netnógrafo (KOZINETS, 2010) e se apresentam como páginas da web ou de textos coletados antes mesmo de o pesquisador “entrar" em campo. Neste artigo, o dado de arquivo apresentado será um post de Facebook em que é realizada uma atualização de status na seção "No que você está pensando?". Além dos dados de arquivo, a netnografia também faz uso de dados suscitados. Nesse tipo de procedimento, o netnógrafo e os participantes da pesquisa co-constroem sentidos através de ferramentas interativas. Isso pode ocorrer na forma de comunicação assíncrona, seja através de postagem de perguntas em fóruns, assim como através do envio de questionários por e-mail ou ainda de forma síncrona como a realização de entrevistas por meio do Skype e equivalentes. Em meu contexto de pesquisa, foi dado prioridade ao envio 
de questionários, à condução de entrevistas no próprio chat do Facebook e ao envio de perguntas por $e$-mail.

Por fim, semelhante às notas de campo na etnografia, os dados de anotação acrescentam as impressões e interpretações dos netnógrafos com relação às práticas analisadas. Nessa anotação de campo reflexiva, o netnógrafo relata suas próprias observações concernentes aos textos, subtextos e condições pessoais, emocionais e identitárias envolvidas no estudo. Para Kozinets (2010), essas anotações oferecem detalhes sobre os processos sociais e interacionais nos quais os participantes da pesquisa se envolvem.

Feitas as considerações sobre a forma de geração de dados, partirei para a apresentação do sujeito e do post escolhido para análise.

\section{Sobre o sujeito}

A participante escolhida para este estudo foi " $\mathrm{E}$ ", , uma mulher de trinta e três anos, nascida no Quênia. Assim como os demais sujeitos da pesquisa, "E" já fazia parte de minha rede de "amigos" no Facebook, como decorrência de uma experiência que tivemos com ensino de línguas nos Estados Unidos. O seu perfil, assim como os dos demais participantes, se encaixava nos critérios estabelecidos para participação na pesquisa, pois além de ter vivido em um país que sofreu um longo período de colonização, os seus posts apresentavam combinações e mesclas de diferentes recursos multissemióticos. "E" já viveu em diferentes países como na Coreia do Sul por quase dois anos, Japão por dois meses e Estados Unidos por três anos. Ela possui mestrado e já foi professora numa universidade dos Estados Unidos. Atualmente, "E" reside no Quênia.

Quando criança, ela foi exposta a mais de dez línguas, mas afirma se comunicar melhor em três delas: inglês, suaíli e luia. Além de empregar recursos dessas línguas em seu dia a dia, ela consegue se comunicar, relativamente bem, em japonês, kikuyu e francês. Sua página do Facebook conta com mais de mil "amigos", possível consequência de sua trajetória como um sujeito "transnacional" (WEI; HUA, 2013). Ela atualiza sua rede social quase que diariamente através de posts que tratam de suas viagens, de sua vida

\footnotetext{
${ }^{9}$ Pseudônimos foram usados no intuito de preservar a anonimidade dos participantes da pesquisa.
} 
como casada e das diferenças culturais entre o Quênia e os Estados Unidos. Suas práticas no Facebook mostram claramente sua preferência pelo que conhecemos como língua inglesa, porém, observa-se que essa língua está sempre imbricada/combinada com outros recursos linguísticos.

As práticas translíngues de "E" envolvem a mistura de variados recursos linguísticos, paralinguísticos e multissemióticos. Em grande parte de seus posts, há a combinação de onomatopeias online, emojis/emoticons, memes e a mistura de recursos de línguas que, tradicionalmente, conhecemos como inglês e suaíli. Porém, recursos de outras línguas também podem ser vistos com menor incidência, como no emprego de expressões em japonês e luia.

Os dados, a seguir, foram gerados a partir de análises prévias do post, de um questionário sociolinguístico enviado à participante, assim como de anotações das práticas digitais nas quais ela se envolve e de entrevistas conduzidas na própria plataforma do Facebook, a fim de se obter sua perspectiva sobre a prática estudada.

\section{Sobre a análise e discussão dos dados}

O post escolhido se trata de uma atualização de status, em que "E" tece críticas a um polêmico blogger queniano. Nele, a participante não apenas assume determinados posicionamentos identitários, como também resiste a posições atribuídas a ela e a outros sujeitos.

Tabela 01:

\section{TEXTO DO FACEBOOK ${ }^{10}$}

\footnotetext{
${ }^{10}$ Foi usado o recurso de print de tela para se obter o post tal como publicado na rede social. Dados que pudessem identificar os sujeitos (fotos de perfis, nomes etc.) foram apagados. Os próprios participantes da pesquisa realizaram a tradução para o inglês das línguas que não eram do meu conhecimento. A partir da versão em língua inglesa, traduzi os textos para o português.
} 
January $8 \cdot 26$

Haki mimi nimeketi kuangalia wall yangu ya FB na nika-stumble upon huyu mtu anajita Cyprian, Is Nyakundi. Haki I want my five minutes back!

See Translation

凹 Like $\square$ Comment

\section{$\ddot{10} 5$}

Me too baby!

Like - Reply - 22w

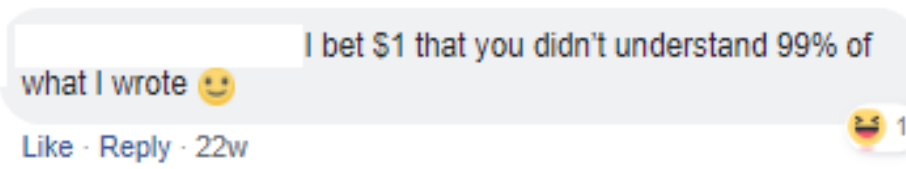

You better have that $\$ 1$ waiting for me when $\mathrm{i}$ pick you up from the airport baby! is

$1 \mathrm{hr} \cdot \mathrm{st}$

Haki mimi nimeketi kuangalia wall yangu ya FB na nika-stumble upon huyu mtu anajita Cyprian, is Nyakundi. Haki I want my five minutes back!

I am just sitting looking at my facebook wall and I have been seated on this one, he is calling for a community, is in nyakach. I want my five minutes back!

(C) - Rate this translation

Like - Reply - 22 w

Google translate is a liar.

Like - Reply $\cdot 22 w$

\section{TRADUÇÃO}

"E": Eu juro que eu estava sentada aqui dando uma olhada em meu Facebook e me deparei com esse cara que se chama de Cyprian, Is Nyakundi. Juro que eu quero meus cinco minutos de volta!

"SUJEITO 2": Eu também baby!

\section{COMENTÁRIOS}

"E": Eu aposto 1 dólar que você não entendeu $99 \%$ do que eu escrevi ?]

"SUJEITO 2": É melhor você ter esse 1 dólar me esperando quando eu for te buscar no aeroporto, baby! 


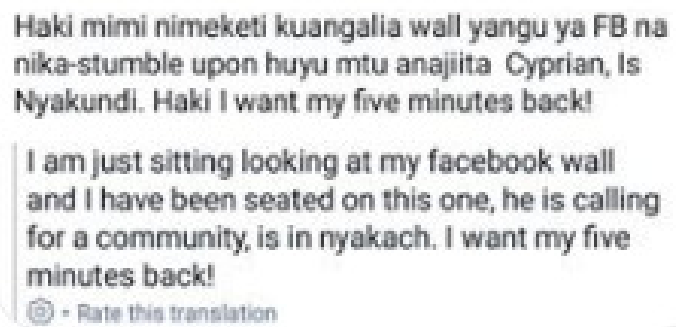

"E”: Não foi nada disso o que eu disse!! O Google translate é um mentiroso.

\section{Fonte: elaborado pelo autor.}

Levando em consideração as perspectivas sobre processos identitários aqui discutidas, me inclino a dizer que há, pelo menos, duas camadas principais de posicionamentos identitários desenvolvidos por/nesse texto. A primeira delas diz respeito à postura de "E" sobre as colocações do blogger Cyprian, Is Nyakundi, e a segunda está relacionada ao posicionamento de um dos seus "amigos" quanto a uma das posições atribuídas a ele pelo post.

Cyprian, Is Nyakundi é famoso no Quênia por suas declarações tidas como machistas e preconceituosas direcionadas, principalmente, às mulheres quenianas. Em uma de suas entrevistas a uma emissora de rádio (KASUJJA, 2017), por exemplo, Cyprian tratou de forma trivial um caso de violência sexual no Quênia, dando a entender que nenhum homem teria vontade de violentar uma mulher como a vítima, o que indica a preocupante ideia de que existiriam mulheres que levariam os homens a terem o desejo de violentá-las. Tais declarações são alvos constantes de protestos, pois evidenciam que discursos históricos que inferiorizam as mulheres nas sociedades daquele país ainda estão vivos e são endossados por parte da população (a julgar pelo crescente número de seguidores do blogger).

No post em questão, é possível observar um caso de posicionamento de terceira ordem que se dá através da negociação de novos direitos e deveres. Isso pode ser notado quando "E" assume uma postura afetiva ao afirmar: "Juro que eu quero meus cinco minutos de volta", indicando a sua desaprovação quanto ao posicionamento de primeira ordem que Nyakundi atribui às mulheres quenianas e, consequentemente, a ela. Nesse ato, "E" não só contesta a linha narrativa sugerida pelo queniano, como também reivindica para si o direito de se posicionar, atribuindo ao blogger, ao mesmo tempo, uma possível 
posição de homem machista. Situo esse posicionamento como de terceira ordem, uma vez que o ato de reposicionamento ocorre em um novo contexto e não na mesma interação em que o primeiro posicionamento é efetuado.

Esses atos são alcançados através do processo de recontextualização das falas de Cyprian, Is Nyakundi (que não são descritas pela participante) em um novo contexto (o próprio post de "E", publicado em sua rede social). Esse processo de recontextualização, ligado ao que Bauman e Briggs (1990) chamam de entextualização, está no centro dos posicionamentos identitários contemporâneos. Para esses autores, a entextualização é o processo de tornar um discurso passível de ser extraído, de transformar um trecho de uma outra esfera comunicativa em uma unidade que pode ser deslocada de seu cenário interacional. Nesse sentido, um texto é um discurso tornado passível de descontextualização.

Esses processos de entextualização/descontextualização levam, então, os textos a serem recontextualizados em novos contextos sociais, estando eles abertos a negociação de outros sentidos. Com base no exposto, é possível perceber que é nessa relação entre processos de re/descontexualização e atribuição de novos direitos e deveres que "E" confronta o posicionamento do blogger queniano.

A escolha lexical e de demais recursos semióticos também acentua diferentes posturas adotadas por "E". Ao fazer uma avaliação crítica das posições assumidas por Nyakundi, ela expressa seus sentimentos pessoais, atitudes e juízo de valor, indicando sua postura afetiva. Entretanto, muitas declarações desse tipo nem sempre deixam clara a fronteira entre essas e as posturas epistêmicas, por exemplo. Dessa forma, para um debate produtivo sobre os posicionamentos se faz necessária uma abordagem multidimensional, lançando mão de uma combinação de análise linguística e intuições (n)etnográficas (BARTON; LEE, 2015).

O fato de "E" demonstrar seu descontentamento com a posição de Nyakundi a partir de variados recursos linguísticos também dá pistas de sua identidade multilíngue, projetando-a como um sujeito que transita entre diferentes contextos étnico-culturais. Nesse sentido, "E" assume uma postura epistêmica, já que esse autoposicionamento indexa (BAKHTIN, 1981) seu background multilíngue.

Ao se valer de recursos linguísticos do que, comumente, conhecemos como suaíli e 
inglês, "E" não só se posiciona como um sujeito multilíngue, mas também convoca uma audiência específica a participar de seu post, a saber, aquela que entende suaíli e inglês, o que exclui, consequentemente, parte de seus mil "amigos" que não compartilha os mesmos recursos. Em outros termos, "E" se envolve em uma prática de constante negociação semiótica, em que a escolha de suas línguas muda à medida que as relações que ela quer estabelecer com o seu público-alvo também mudam. Tal aspecto foi abordado pela participante nas entrevistas conduzidas, nas quais sempre enfatizava que a escolha desses recursos era consciente, uma vez que ao lançar mão de determinadas línguas, ela buscava direcionar o seu texto a uma audiência específica, impedindo, assim, a participação de outras.

Quando questionada sobre o porquê da mistura de recursos linguísticos em um único post, "E" afirma: "Depende do meu público alvo. Então, depende se estou apontando para meus amigos do Japão, para os meus amigos falantes de francês ou se eu quero excluir meus amigos americanos" (Entrevista) ${ }^{11}$. A partir dessa declaração, fica mais evidente que a escolha de recursos é, em sua grande parte, um processo consciente de estabelecimento de relações e de diferentes posições identitárias. Entretanto, mesmo tendo como alvo audiências distintas, as possibilidades oferecidas pela comunicação digital colocam em xeque as relações de poder estabelecidas pelas práticas translíngues de "E", o que nos leva à segunda camada de negociação identitária, envolvendo a sua interação com o "Sujeito 2".

A partir do momento em que escreve o seu texto para uma audiência específica, consciente de que outra seria excluída da interação, a participante atribui diferentes posições aos seus "leitores". Desse modo, escrever um post "bilíngue" com recursos do suaíli e inglês, ao mesmo tempo em que atribui direitos e deveres específicos, posicionando falantes dessas duas línguas como "autorizados" e no direito de participar/comentar a publicação, posiciona todos os demais como "não autorizados".

Entretanto, como já discutido neste texto, o posicionamento é um ato interativo, o que significa dizer que a maneira como os sujeitos entendem as posturas de "E" pode moldar novas enunciações e negociações. Em sites de rede social, como o Facebook, “[...] a postura não é adotada por um único falante ou escritor, mas é constantemente criada e

\footnotetext{
${ }^{11}$ As entrevistas foram realizadas em língua inglesa. As traduções para o português são de minha 
renegociada de forma colaborativa por um público em rede [...]” (BARTON; LEE, 2015, p. 50). Portanto, esses atos de posicionamento multimodal-multilíngue, apesar de serem autogerados, acabam se tornando coparticipativos (BARTON; LEE, 2015). No post analisado, mesmo tendo o "cuidado" de abordar apenas uma audiência "bilíngue", "E" não tinha controle de quem, de fato, poderia ler e interagir em suas publicações. Esse fato é perceptível através do envolvimento do "Sujeito 2", quem, supostamente, não teria o direito de participar.

Ao postar "Eu também, baby", o "Sujeito 2" passa a negociar a posição de "não autorizado" que lhe fora atribuída através da manipulação dos recursos linguísticos que compõem o repertório de "E", reivindicando, assim um novo conjunto de direitos e deveres. Como o post indica, o repertório semiótico daquele sujeito não apresenta elementos suficientes que indiquem seu conhecimento da língua suaíli. É possível fazer essa afirmação porque "E", em "tom" de brincadeira (o que pode ser inferido pela combinação do emoji sorridente e pela relação que os dois têm de marido e mulher) responde duvidando da capacidade do "Sujeito 2" ter compreendido a postagem. Isso fica evidente na postura epistêmica de "E", ao declarar: "Eu aposto 1 dólar que você não entendeu 99\% do que eu escrevi (-)", como também quando o "Sujeito 2" posta uma tradução automática do texto publicado na atualização de status.

A negociação continua na seção de comentários em que é possível observar "E" questionando a validade da tradução automática e, constantemente, posicionando o "Sujeito 2" como "não autorizado" a participar de sua postagem. Porém, essas posições são resistidas através de recursos disponíveis para esse tipo de interação digital, como a tradução automática de textos em língua estrangeira oferecida pelo próprio Facebook.

Com isso, percebe-se que a manipulação de diferentes recursos semióticos em textos online aponta para camadas complexas de negociação de posições identitárias. Sujeitos que, comumente, são tomados como "monolíngues", como pode ser o caso do "Sujeito 2", desafiam o rótulo através das possibilidades oferecidas pela tecnologia digital, indicando, assim, posições identitárias locais e transitórias expressas pela combinação de recursos linguísticos fluidos, ressaltando a necessidade da adoção de perspectivas translíngues para a elucidação de tais práticas. Além desses aspectos, a análise da primeira

responsabilidade. 
camada de posicionamentos indica que performances repetidas que instituem discursos limitadores sobre o que vem a ser identidade de gênero no Quênia, por exemplo, são desafiadas por "E" através de atos discursivos que apontam para a não aceitação de práticas que vêm, historicamente, subalternizando determinados sujeitos. A combinação entre recursos de línguas tidas como "minoritárias" com recursos do inglês indica a posição de "E" como uma usuária glocal ${ }^{12}$ de redes sociais, expressando suas diferentes identidades linguísticas e tornando visível práticas de linguagem pouco debatidas na grande rede. Escrever de modo multilíngue, nesse sentido, se configura como uma estratégia de resistência (CANAGARAJAH; DOVCHIN, 2019), em que sujeitos celebram suas práticas comunicativas offline em espaços digitais ainda dominados por discursos homogeneizantes sobre língua e identidade.

\section{SOBRE AS (IN)CONCLUSÕES}

As novas mídias digitais, como as plataformas de redes sociais, têm permitido aos sujeitos construir, moldar e ressignificar diferentes posições identitárias através de recursos multimodais. Dessa forma, é possível afirmar que as práticas de linguagem de multilíngues seriam um caminho para que esses afirmem sua existência através de diferentes modos de leitura e escrita. Assim, ao escrever um post de Facebook, por exemplo, os sujeitos estão construindo narrativas de si mesmos, em que diferentes posições assumidas no discurso indexam novas identidades, sejam elas comumente definidas como on ou offline.

No Facebook, quando usuários postam suas atualizações de status, estão almejando envolver grupos específicos, podendo incluir "amigos" de diferentes backgrounds linguísticos. Assim, a escolha de recursos linguístico-semióticos depende não só do conteúdo postado, como também do público-alvo da atualização. De modo similar, o espaço de comentários pode oportunizar uma variedade de escolhas linguísticosemióticas de acordo com os repertórios dos sujeitos envolvidos e dos propósitos comunicativos. Como "escritores" e "leitores" de posts de Facebook empregam uma

\footnotetext{
${ }^{12}$ Para os autores, essa é uma maneira de participar de processos de negociação de identidades locais com elementos de culturas e identidades globais. Dessa forma, os sujeitos conseguem explicar ou dar pistas de suas culturas e posicionamentos a diferentes audiências, sejam elas locais ou globais.
} 
variedade de recursos para construir sentido, a escolha desses serve como uma importante estratégia de posicionamento identitário na grande rede.

Por essas razões, a perspectiva da translinguagem pode ser um caminho produtivo para se analisar e compreender as práticas de linguagem de sujeitos multilíngues. Sua proposta desloca a visão de língua como um sistema autônomo e fechado em si mesmo para a noção de prática social, configurando, assim, uma ruptura paradigmática nos estudos da linguagem (ROCHA; NETO, 2020). Neste artigo, portanto, os pressupostos da translinguagem, bem como da Teoria dos Posicionamentos/postura me permitiram discutir, mesmo que brevemente, como intensas mesclas de recursos multissemióticos de sujeitos multilíngues pode apontar para diferentes processos de posicionamentos identitários no Facebook.

Finalizo esclarecendo que este texto apresenta apenas um recorte de uma pesquisa maior no campo da Linguística Aplicada. Por esse motivo, acredito que pesquisadores interessados na temática aqui tratada precisam estar conscientes que os dados não devem ser tomados como universais e nem homogeneizantes, demandando assim, um cuidado com o desenvolvimento de novas pesquisas na área. Adiciono a esse fato a importância de se investigar os posicionamentos dos próprios pesquisadores no processo de geração e de tratamento dos dados, o que, devido ao escopo deste artigo não foi possível explorar, bem como priorizar estudos com sujeitos pouco ouvidos em pesquisas dessa natureza, como as chamadas vozes do sul (SANTOS; MENESES, 2010). Dessa forma, poderemos discutir, com mais atenção, de que maneiras os sujeitos se valem de estratégias multilíngues para transformar suas realidades locais, bem como resistir a discursos que inferiorizam as suas identidades.

\section{REFERÊNCIAS}

AUSTIN, J. Quando dizer é fazer: palavras e ação. Tradução de Danilo Marcondes de Souza Filho. Porto Alegre: Artes Médicas, 1990 [1962].

BAUMAN, R.; BRIGGS, C. Poética e Performance como perspectivas críticas sobre a linguagem e a vida social. Tradução de Vânia Z. Cardoso. ILHA, Revista de Antropologia, p. $185-229,1990$. 
BAKHTIN, M. The dialogic imagination: four essays by M. M. Bakhtin. Tradução de Michael Caryl Emerson e Michael Holquist. Austin, TX: Texas University Press, 1981.

BAKHTIN, M/VOLOCHINOV, V. M. Marxismo e filosofia da linguagem. Tradução de Michel Lahud e Yara Frateschi Vieira, 7. ed. São Paulo: Hucitec, 1995 [1929].

BARTON, D; LEE, C. Linguagem online: textos e práticas digitais. Tradução de Milton Camargo Mota. São Paulo: Parábola, 2015.

BLOMMAERT, J. The sociolinguistics of globalization. Cambridge: Cambridge University Press, 2010.

BLOCK, D. The social turn in second language acquisition. Washington, DC: Georgetown University Press, 2003.

BOLANDER, B.; LOCHER, M. A. Constructing identity on Facebook: report on a pilot study. In: KUNOD, K.; MAILLAT, D. (Org.). Constructing the self. Tübingen: NarrFrancke, 2010, p. 165-185.

BOLANDER, B.; LOCHER, M. A. Peter is a dumb nut: status updates and reactions to them as 'acts of positioning' in Facebook. Pragmatics, v. 25, n. 1, p. 99-122, 2015.

BOLANDER, B. Language and identity on Facebook. In: THORNE, S.L.; MAY, S. (Org,). Language, education and technology. Encyclopedia of language and education. Springer International Publishing, 2017, p. 143-153.

BROWN, A. D. Identities and identity work in organizations. International Journal of Management Review, v. 17, p. 20-40, 2015.

BUCHOLTZ, M.; HALL, K. Identity and interaction: a sociocultural linguistic approach. Discourse Studies 7, v. 4, n. 5, p. 584-614, 2005.

BUTLER, J. Gender trouble: feminism and the subversion of identity. London: Routledge, 1990.

CANAGARAJAH, A. S. Translingual practice: global Englishes and cosmopolitan relations. New York: Routledge, 2013.

CANAGARAJAH, A. S. Translingual practices and neoliberal policies: attitudes and strategies of African skilled migrants in Anglophone workplaces. Switzerland: Springer, 2017.

CANAGARAJAH, A. S.; DOVCHIN, S. The everyday politics of translingualism as a resistant practice. International Journal of Multilingualism, v. 16, n. 2, p. 127-144, 2019.

COUPLAND, N. Style: language variation and identity. Cambridge: Cambridge University Press, 2007. 
CREESE, A.; BLACKLEDGE, A. Translanguaging in the bilingual classroom: a pedagogy for learning and teaching? The Modern Language Journal, v. 94, n. 1, p. 103$115,2010$.

DAVIES, B.; HARRÉ, R. Positioning: the discursive production of selves. Journal for the Theory of Social Behaviour, v. 20, n. 1, p. 43-63, 1990.

DEPPERMANN, A. Positioning. In: DE FINA, A.; GEORGAKOPOULOU, A. (Org.). The handbook of narrative analysis. Malden, MA: Wiley, 2015, p. 369-387.

DIGITAL 2019: Global digital overview. DATAREPORTAL, 2019. Disponível em: $<$ https://datareportal.com/reports/digital-2019-global-digital-overview $>$. Acesso em $29 \mathrm{de}$ jun. 2020.

FOUCAULT, M. A Arqueologia do Saber. Rio de Janeiro: Forense Universitária, 2009 [1969].

GARCÍA, O. Bilingual education in the 21 st century: a global perspective. Oxford: WileyBlackwell, 2009.

GARCÍA, O.; WEI, L. Translanguaging: language, bilingualism, and education. New York: Palgrave MacMillan, 2014.

GOFFMAN, E. A representação do eu na vida cotidiana. Edinburgh: University of Edinburgh Press, 1959.

GUMPERZ, J. J. Discourse strategies. Cambridge: Cambridge University Press, 1982.

HARRÉ, R.; GILLETT, G. The discursive mind. Thousand Oaks, C: Sage, 1994.

HARRÉ, R; VAN LANGENHOVE, L. Positioning theory: moral contexts of intentional action. Oxford: Blackwell, 1999.

HARRÉ, R.; SLOCUM, N. Disputes as complex social events: on the uses of positioning theory. In: HARRÉ, R.; MOGHADDAM, F. (Org.). The self and others: positioning individuals and groups in personal, political, and cultural contexts. Westport, CT and London: Praeger, 2003, p. 123-136.

HERBEL-EISENMANN， B. A.; WAGNER， D.; JOHNSON， K. R.; SUH, H.; FIGUERAS, H. Positioning in mathematics education: revelations on an imported theory. Educational Studies in Mathematics, v. 89, n. 2, p. 185-204, 2015.

KASUJJA, M. Blogger Nyakundi under fire for outrageous rape post on Adele Onyango. Disponível em: <https://nairobinews.nation.co.ke/news/cyprian-nyakundi-rape-adelleonyango $>$. Acesso em 30 jun. 2020.

KAYI-AIDAR, H. Positioning theory in applied linguistics: research, design \& 
applications. Tucson, AZ: Palgrave Macmillan, 2019.

KOZINETS, R. Netnography: doing ethnographic research online. Londres: Sage, 2010.

KOZINETS, R. V. Netnography: the essential guide to qualitative social media research. London: Sage, 2020.

KRESS, G.; VAN LEEUWEN, T. Multimodal discourse: the modes of media of contemporary communication. New York: Oxford University Press, 2001.

LEPPÄNEN, S.; MØLLER, J. S.; NØRREBY, T. R.; STAEHR, A.; KYTÖLA, S. Authenticity, normativity and social media. Discourse, Context \& Media, v. 8, p. 1-5, 2015.

MACIEL, R. F.; ROCHA, C. H. Dialogues on translingual research and practice: weaving threads with Suresh Canagarajah's views. Revista X, v. 15, n. 1, p. 07-31, 2020.

MARWICK, A. E.; boyd, d. I tweet honestly, I tweet passionately: twitter users, context collapse, and the imagined audience. New Media \& Society, v. 20, n. 10, p. 1-20, 2010.

MOITA LOPES, L. P. da. (Org.). Linguística aplicada na modernidade recente: festschrift para Antonieta Celani. São Paulo: Parábola, 2013.

MYERS, G. Discourse of blogs and wikis. Londres/Nova York: Continuum, 2010.

MYERS-SCOTTON, C. Social motivations for codeswitching: evidence from Africa. Oxford: Clarendon Press, 1993.

PAVLENKO, A.; BLACKLEDGE, A. Negotiation of identities in multilingual contexts. Multilingual Matters LTD., 2004.

PENNYCOOK, A. Global Englishes and transcultural flows. London, New York: Routledge, 2007.

PENNYCOOK, A. Translingual English. Australian Review of Applied Linguistics, v. 31, n. 3, p. 1-9, 2008.

PENNYCOOK, A.; OTSUJI, E. Metrolingualism: language in the city. Oxon, UK: Routledge, 2015.

ROCHA, C. H.; MACIEL, R. F. Ensino de língua estrangeira como prática translíngue: articulações com teorizações bakhtinianas. D.E.L.T.A., São Paulo, v. 31, n. 2, p. 411-445, 2015.

ROCHA, C. H.; NETO, A. T. Translinguagens: discurso, políticas e pedagogias. Editorial. Revista X, v. 15, n. 1, p. 01-06, 2020. 
ROJO, R. Pedagogia dos multiletramentos: diversidade cultural e de linguagens na escola. In: ROJO; R.; MOURA, E. (Org.). Multiletramentos na escola. São Paulo: Parábola Editorial, 2012, p. 11-31.

SAITO, F. S.; RIBEIRO, P. N. de S. (Multi)Letramento(s) digital(is), teoria do posicionamento e identidade docente: como professoras de uma escola pública juiz-forana se localizam metaforicamente na era digital. Revista Práticas de Linguagem, v. 3, n. 2, p. 105-121, 2013.

SANTOS, B. S.; MENESES, M. P. (Org.). Epistemologias do Sul. São Paulo: Cortez, 2010.

SHARMA, B. K. Beyond social networking: performing global Englishes in Facebook by college youth in Nepal. Journal of Sociolinguistics, v. 16, n. 4, p. 483-509, 2012.

SLOCUM-BRADLEY, N. The positioning diamond: a transdisciplinary framework for discourse analysis. Journal of the Theory of Social Behaviour, v. 40, p. 80-107, 2008.

SULTANA, S.; DOVCHIN, S.; PENNYCOOK, A. Styling the periphery: linguistic and cultural take up in Bangladesh and Mongolia. Journal of Sociolinguistics, v. 14, n. 4, p. 671-687, 2013.

SULTANA, S.; DOVCHIN, S.; PENNYCOOK, A. Transglossic practices of young adults in Bangladesh and Mongolia. International Journal of Multilingualism, v. 12, n. 1, p. 93$108,2015$.

SEARLE, J. R. Expression and meaning: studies in the theory of speech acts. Cambridge, London, New York, Melbourne: Cambridge University Press, 1979.

TAN, S. L.; MOGHADDAM, F. M. Reflexive positioning and culture. Journal for the Theory of Social Behaviour, v.25, n. 4, p. 387-400, 1995.

WEI, L; HUA, Z. Translanguaging identities and ideologies: creating transnational space through flexible multilingual practices amongst Chinese university students in the UK. Applied Linguistics, v. 34, n. 5, p. 516-535, 2013.

WEI, L. Translanguaging as a practical theory of language. Applied Linguistics, v.39, n.2, p. 1-23, 2018.

ZHAO, S.; SHERRI, G.; MARTIN, J. Identity construction on Facebook: digital empowerment in anchored relationships. Computers in Human Behaviorv. 24, p. 18161836, 2008. 